This document is confidential and is proprietary to the American Chemical Society and its authors. Do not copy or disclose without written permission. If you have received this item in error, notify the sender and delete all copies.

\title{
Efficient isomerization of a-pinene oxide to campholenic aldehyde promoted by a mixed-ring analogue of molybdenocene
}

\begin{tabular}{|c|c|}
\hline Journal: & ACS Sustainable Chemistry \& Engineering \\
\hline Manuscript ID & sc-2019-030878.R1 \\
\hline Manuscript Type: & Letter \\
\hline $\begin{array}{r}\text { Date Submitted by the } \\
\text { Author: }\end{array}$ & 12-Jul-2019 \\
\hline Complete List of Authors: & $\begin{array}{l}\text { Bruno, Sofia; Universidade de Aveiro, Chemistry } \\
\text { Valente, Anabela; Universidade de Aveiro, } \\
\text { Pillinger, Martyn; Universidade de Aveiro, Chemistry } \\
\text { Amelse, Jeffrey; University of Aveiro, Department of Chemistry, CICECO } \\
\text { - Aveiro Institute of Materials } \\
\text { Romão, Carlos C.; Universidade Nova de Lisboa Instituto de Tecnologia } \\
\text { Quimica e Biologica, } \\
\text { Gonçalves, Isabel; Universidade de Aveiro, Chemistry }\end{array}$ \\
\hline
\end{tabular}

\section{SCHOLARONE ${ }^{\text {m }}$ Manuscripts}




\title{
Efficient isomerization of $\alpha$-pinene oxide to campholenic aldehyde promoted by a mixed-ring analogue of molybdenocene
}

\author{
Sofia M. Bruno ${ }^{\dagger}$ Anabela A. Valente, ${ }^{*, \dagger}$ Martyn Pillinger ${ }^{\dagger}$ Jeffrey Amelse, ${ }^{\dagger}$ Carlos C. \\ Romão, $₫$ and Isabel S. Gonçalves*,† \\ $\dagger$ Department of Chemistry, CICECO - Aveiro Institute of Materials, University of Aveiro, Campus \\ Universitário de Santiago, 3810-193 Aveiro, Portugal \\ † Instituto de Tecnologia Química e Biológica, Universidade Nova de Lisboa, Av. da República, EAN, \\ 2780-157 Oeiras, Portugal
}

Corresponding Authors

*E-mail: atav@ua.pt; Tel.+351-234370603

*E-mail: igoncalves@ua.pt; Tel.+351-234370096

KEYWORDS: Renewable resources, Terpenes, Rearrangement, Homogeneous catalysis, Molybdenum, Metallocenes, Lewis acids, Ionic liquids

\begin{abstract}
The Mo ${ }^{\mathrm{IV}}$ complex $\left[\left(\eta^{5}\right.\right.$-indenyl $)\left(\eta^{5}\right.$-cyclopentadienyl $\left.) \mathrm{Mo}(\mathrm{MeCN})_{2}\right]\left(\mathrm{BF}_{4}\right)_{2}(\mathbf{1})$ has been used to promote two acid-catalyzed epoxide ring-opening reactions under ambient conditions. The alcoholysis of styrene oxide in neat ethanol gave 2-ethoxy-2-phenylethanol in quantitative yield within $10 \mathrm{~min}$. The use of an ionic liquid (IL) as cosolvent benefitted catalyst solubility and recycling while not impairing catalytic performance. Complex 1 in 1,2dichloroethane was effective for the isomerization of $\alpha$-pinene oxide to campholenic aldehyde (CPA), leading to $87 \%$ yield at $1 \mathrm{~h}$ reaction. The same yield could be achieved within $1 \mathrm{~min}$ by using the IL [Choline][ $\left.\mathrm{NTf}_{2}\right]$ as solvent. CPA yields at 1 min reached near-quantitative values (98\%) upon recycling of the catalyst/IL mixture, demonstrating an unparalleled combination of activity, selectivity and recyclability for this commercially important reaction. Considering the catalytic features of the $1 / \mathrm{IL}$ system, a CPA process flow diagram is proposed and compared to patented technology.
\end{abstract}

\section{INTRODUCTION}

Epoxides are important building blocks in organic synthesis owing to their ability to undergo 
various types of ring-opening reactions. ${ }^{1-4}$ For these processes to be of practical use, mild reaction conditions are desirable and the selectivity towards the target product must be high. These requirements usually demand the use of an acid or base catalyst. Two synthetically valuable acid-catalyzed reactions are ring-opening with nucleophiles to give 1,2-disubstituted products, and Meinwald rearrangement to give aldehydes and ketones. ${ }^{4}$ The first reaction generates $\beta$-substituted alcohols such as $\beta$-aminoalcohols and $\beta$-alkoxyalcohols, ${ }^{5-6}$ which have important pharmacological properties, biological activities, and are useful synthetic reagents, particularly as chiral auxiliaries. An important example of the second reaction is the acidpromoted isomerization of $\alpha$-pinene oxide (PinOx) to campholenic aldehyde (CPA) (Scheme 1). ${ }^{7-10}$ PinOx originates from the epoxidation of $\alpha$-pinene, which is the most abundant terpene in nature and is obtained industrially from turpentine, a byproduct of the wood pulping process to produce paper. The classical process for the preparation of PinOx is the so-called Prilezhaev reaction, i.e. epoxidation of $\alpha$-pinene by means of peroxycarboxylic acids in stoichiometric amounts. A lot of progress has been made towards the development of more sustainable methods to produce PinOx, e.g. methyltrioxorhenium-catalyzed epoxidation with hydrogen peroxide, ${ }^{11}$ and ultrasonic and catalyst-free epoxidation using dimethyl dioxirane. ${ }^{12}$

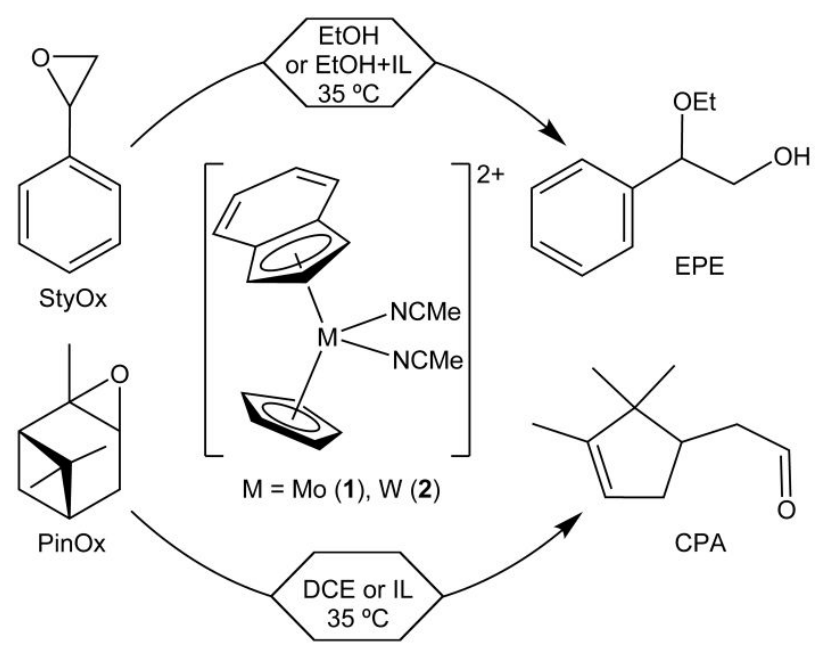

Scheme 1. Ethanolysis of styrene oxide to give 2-ethoxy-2-phenylethanol, and isomerization of $\alpha$-pinene oxide to campholenic aldehyde, in the presence of $\mathbf{1}$ and $\mathbf{2}$ (DCE = 1,2-dichloroethane; $\mathrm{IL}=$ ionic liquid).

The main value of CPA is as an intermediate in the synthesis of fragrances such as 
naturanol ${ }^{13}$ and sandalwood-type odorants. ${ }^{14}$ CPA has also been explored as a chiral starting material in the synthesis of cyclopentanoid chiral synthons, which have utility in the synthesis of natural products. ${ }^{15}$

PinOx isomerization is a complex reaction that can give more than 200 different products if run at temperatures higher than $100{ }^{\circ} \mathrm{C},{ }^{16,17}$ with examples of the more common ones being CPA, trans-carveol, trans-sobrerol, iso-pinocamphone and pinocarveol. The formation of CPA is favored in the presence of Lewis acids. Traditionally, zinc halides have been considered to be the state-of-the-art homogeneous catalysts, giving CPA selectivities up to about $85 \% .{ }^{18}$ Patented technologies of CPA production comprise feeding continuously PinOx to a mixture of a Lewis acid catalyst (e.g. zinc bromide or zinc chloride) and a solvent that has a higher boiling point than CPA (e.g. diphenyl ether), operating under conditions to favor very high conversion, which is followed by the separation of CPA via vacuum distillation. ${ }^{19}$ Several shortcomings of this process, such as catalyst deactivation, difficulty in catalyst recycling and toxic zinc-containing waste disposal issues, have motivated studies on the development of alternative homogeneous or heterogeneous catalytic systems for the selective synthesis of CPA from PinOx. A major challenge is to unite high activity and high CPA selectivity. In this direction, promising developments of catalytic routes to PinOx have appeared in the literature. Pitínová-Štekrová et al. reported that the reaction of PinOx over a Ti-MCM-22 catalyst in toluene at $70{ }^{\circ} \mathrm{C}$ led to total conversion within $1 \mathrm{~h}$ and a CPA selectivity of $96 \%{ }^{20}$ This result was deemed to substantially exceed all other previously published results, although recovery/reuse of the catalyst was not reported.

We have determined that molybdenum dicarbonyl, tricarbonyl and tetracarbonyl complexes can effectively promote the isomerization of PinOx to CPA, ${ }^{21-23}$ and the alcoholysis of epoxides. ${ }^{23-25}$ All the complexes studied led to 100\% selectivity towards 2-ethoxy-2phenylethanol (EPE) in the ethanolysis of styrene oxide (StyOx), with the $\eta^{5}$-indenyl complex $\left[\right.$ IndMo $\left.(\mathrm{CO})_{2}(\mathrm{MeCN})_{3}\right] \mathrm{BF}_{4}$ being particularly active (full conversion after $1 \mathrm{~min}$ at $35^{\circ} \mathrm{C}$ ). ${ }^{25}$ The best result for the isomerization reaction was a CPA selectivity of $68 \%$ at full conversion (30 min at $35^{\circ} \mathrm{C}$ or $1 \mathrm{~min}$ at $55^{\circ} \mathrm{C}$ ) in the presence of the dinuclear complex [ $\left.\left\{(\mathrm{Ind}) \mathrm{Mo}(\mathrm{CO})_{2}(\mu-\mathrm{Cl})\right\}_{2}\right]$ in 1,2-dichloroethane. ${ }^{22}$

Herein we report a major advance on the PinOx-to-CPA conversion by the use of the organometallic Lewis acid $\left[\mathrm{IndCpMo}(\mathrm{MeCN})_{2}\right]\left(\mathrm{BF}_{4}\right)_{2}(\mathbf{1})$ as catalyst in conjunction with an ionic 
liquid (IL) solvent. Complex 1 was identified as a potentially interesting catalyst for this reaction for a number of reasons: (i) The $\mathrm{Mo}^{\mathrm{IV}}$ center in molybdenocene-derived molecules containing the $\mathrm{Cp}_{2}{ }_{2} \mathrm{Mo}^{2+}$ unit is known to act as a Lewis acid, and the molecules have proven to be efficient catalysts for a number of organic reactions ${ }^{26}$; (ii) the $\mathrm{MeCN}$ ligands in $\mathbf{1}$ are labile, ${ }^{27}$ facilitating partial ligand dissociation and opening up of coordination sites; (iii) indenylmetal complexes have been shown in many instances to be superior catalysts to their cyclopentadienyl counterparts in terms of reactivity, selectivity, and stability, with a common explanation for this being the increased ability of the Ind ligand to undergo ring slippage and thereby open up a coordination site for substrate binding/activation. ${ }^{28}$

With complex 1 and the right choice of IL, a CPA selectivity of up to $98 \%$ has been achieved at complete conversion, under mild reaction conditions $\left(35^{\circ} \mathrm{C}\right)$. Furthermore, the bestperforming IL+catalyst systems can be reused in consecutive cycles without loss of performance. A possible CPA production process using the IL+catalyst combination has been designed and discussed.

\section{RESULTS AND DISCUSSION}

The ability of 1 to promote acid-catalyzed reactions was first assessed by using the formation of EPE from StyOx as a model reaction (Scheme 1). The reaction was initially performed in neat ethanol. Fast reaction kinetics at $35^{\circ} \mathrm{C}$ led to complete StyOx conversion at $10 \mathrm{~min}$ and an initial

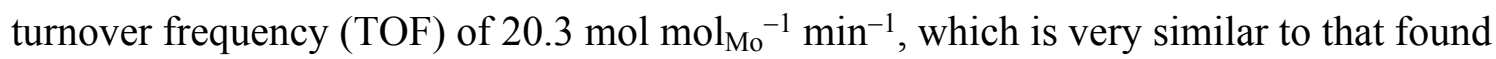
previously for the complex $\left[\mathrm{IndMo}(\mathrm{CO})_{2}(\mathrm{MeCN})_{3}\right] \mathrm{BF}_{4}\left(\right.$ Table 1). ${ }^{25} \mathrm{EPE}$ was always the only product observed. To the best of our knowledge, tungsten carbonyl complexes have not yet been tested for this reaction and therefore the tungsten analogue $\left[\operatorname{IndCpW}(\mathrm{MeCN})_{2}\right]\left(\mathrm{BF}_{4}\right)_{2}(2)$ was prepared. Complex 2 was only slightly less active than 1, leading to a TOF of $17.2 \mathrm{~mol} \mathrm{~mol}_{\mathrm{Mo}^{-1}}$ $\min ^{-1}$ and $100 \%$ EPE yield after $30 \mathrm{~min}$.

Under the reaction conditions used for the ethanolysis of StyOx, complexes $\mathbf{1}$ and $\mathbf{2}$ were only partially soluble. ${ }^{29}$ To completely dissolve the metal complexes, the IL $[\mathrm{bmim}]\left[\mathrm{BF}_{4}\right](\mathrm{bmim}$ =1-butyl-3-methylimidazolium) was used as a cosolvent (EtOH:IL volume ratio = 1:3.3). Both complexes led to $99 \%$ conversion after $1 \mathrm{~min}$ at $35{ }^{\circ} \mathrm{C}\left(\mathrm{TOF}=20.3 \mathrm{~mol} \mathrm{~mol}_{\mathrm{M}}{ }^{-1} \mathrm{~min}^{-1}\right)$, with an EPE selectivity of 100\% (Table 1). With complex 1 EPE was obtained in 100\% yield after 10 min. The reaction without a catalyst gave $23 \%$ conversion at $30 \mathrm{~min}$. A catalytic test for 1 and 2 
under identical conditions, but without IL ([StyOx] $]=0.9 \mathrm{M})$, gave comparable StyOx conversions to those obtained for the corresponding IL-containing system. Hence, the use of an IL enabled solubilization of the complexes but did not affect considerably the catalytic performances.

Table 1. Ethanolysis of StyOx in the presence of complexes 1 and $2^{a}$

\begin{tabular}{|c|c|c|c|c|c|}
\hline Complex & Solvent & Run & {$[$ StyOx $](\mathrm{M})^{b}$} & Time (min) & Conversion $(\%)^{c}$ \\
\hline \multirow[t]{7}{*}{1} & $\mathrm{EtOH}$ & 1 & 0.4 & 1 & 99 \\
\hline & & & & 10 & 100 \\
\hline & $\mathrm{EtOH}$ & 1 & 0.9 & 1 & 99 \\
\hline & $\mathrm{EtOH}-[\mathrm{bmim}]\left[\mathrm{BF}_{4}\right]$ & 1 & 0.9 & 1 & 99 \\
\hline & & & & 10 & 100 \\
\hline & & 2 & 0.9 & 1 & 98 \\
\hline & & & & 10 & 99 \\
\hline \multirow[t]{8}{*}{2} & $\mathrm{EtOH}$ & 1 & 0.4 & 1 & 84 \\
\hline & & & & 10 & 99 \\
\hline & & & & 30 & 100 \\
\hline & $\mathrm{EtOH}$ & 1 & 0.9 & 1 & 84 \\
\hline & & & & 10 & 100 \\
\hline & EtOH-[bmim $]\left[\mathrm{BF}_{4}\right]$ & 1 & 0.9 & 1 & 99 \\
\hline & & 2 & 0.9 & 1 & 98 \\
\hline & & & & 10 & 99 \\
\hline
\end{tabular}

${ }^{a}$ Reaction conditions: $40 \mu \mathrm{mol}$ Mo complex, $0.82 \mathrm{mmol}$ StyOx, solvent [2 $\mathrm{mL}$ EtOH for $[$ StyOx $]=0.4 \mathrm{M} ; 780 \mu \mathrm{L} \mathrm{EtOH}$ or EtOH:IL $(180 \mu \mathrm{L}: 600 \mu \mathrm{L})$ for $[$ StyOx $]=0.9 \mathrm{M}], 35^{\circ} \mathrm{C}$. ${ }^{b}$ Initial StyOx concentration. ${ }^{c} 100 \%$ selectivity to 2 -ethoxy-2-phenylethanol.

One of the advantages of using ILs for homogeneously catalyzed reactions is that the organic products can be readily isolated by extraction/distillation, allowing recycling of the IL/catalyst system..$^{30}$ The IL phases containing 1 or $\mathbf{2}$ were reused after separating the reaction 
product by solvent extraction, and subsequently adding (to the IL) StyOx and EtOH in amounts equivalent to those used in the first batch run. No significant drop in StyOx conversion occurred, suggesting that the promoter/IL systems may be effectively reused, which is important for enhancing the productivity.

The catalytic performance of $\mathbf{1}$ was further explored for the isomerization of PinOx to CPA in 1,2-dichloroethane (Table S1 in the Supporting Information). Complete conversion was reached within $1 \mathrm{~h}$ at $35^{\circ} \mathrm{C}$ with an excellent CPA selectivity of $87 \%$. As shown in Table S1 for the specific case of organometallic promoters, this result has only previously been matched by methyltrioxorhenium(VII) (MTO), which gave the same CPA yield after $1.5 \mathrm{~h}$ reaction at $15^{\circ} \mathrm{C}$ in $\alpha, \alpha, \alpha$-trifluorotoluene. ${ }^{31}$ Even if we widen the scope of the comparison to include various kinds of homogeneous and heterogeneous catalysts reported in the literature (Table S3 in the Supporting Information), there are very few examples of CPA yields higher than $85 \%$. A yield of $93 \%$ was reported for $\mathrm{ZnBr}_{2}$ (toluene, $1 \mathrm{~h}, 25^{\circ} \mathrm{C}$ ), albeit with a large catalyst amount of 68 mol\%..$^{9}$ The metal-organic framework $(\mathrm{MOF})\left[\mathrm{Cu}_{3}(\mathrm{BTC})_{2}\right](\mathrm{BTC}=$ benzene-1,3,5tricarboxylate) displayed high selectivity to CPA (84-86\% in 1,2-dichloroethane or MeCN, 25 ${ }^{\circ} \mathrm{C}$ ), but very long reaction times of several days were required to reach complete conversion. ${ }^{9}$ The best results reported so far for the isomerization of PinOx to CPA were obtained in toluene at $70{ }^{\circ} \mathrm{C}$ with the titanosilicates Ti-MCM-36 (90\% yield, $\left.6 \mathrm{~h}\right)$ and Ti-MCM-22 (96\% yield, 1 h)..$^{20}$

The reaction mechanism of PinOx to CPA may follow similar pathways to those described in the literature for Lewis acid catalysts. ${ }^{8,20,32} \mathrm{~A}$ mechanistic proposal is presented in Figure 1, where [Mo] represents complex 1 . The catalytic cycle may be triggered via a primary activation step involving the coordination of PinOx to the metal center and concomitant epoxide ring opening to give the carbenium ion (I). Subsequently, (I) may rearrange (involving alkyl shifts) to give carbenium ion (II) which, in turn, may undergo C1-C2 bond scission to (III) which ultimately gives CPA. The electronic and steric properties of the catalyst may influence the PinOx activation. The molybdenum catalyst 1 possesses a coordination sphere composed of four simple and relatively small, common organic ligands (robust $\mathrm{Cp}$, and labile $\mathrm{MeCN}$ and Ind) that simultaneously allow the stabilization of $\mathrm{a}+4$ oxidation state for the Mo atom and the structural flexibility needed to sterically facilitate the coordination of the reactant molecules. 
Figure 1. Mechanistic proposal of the conversion of PinOx to CPA in the presence of 1 ([Mo] represents complex 1).

Considering the results obtained using $[\mathrm{bmim}]\left[\mathrm{BF}_{4}\right]$ as a cosolvent in the ethanolysis of StyOx, we further explored the performance of $\mathbf{1}$ for the isomerization of PinOx to CPA using this IL and others as solvents (Table 2). The two tetrafluoroborate ILs [bmim] $\left[\mathrm{BF}_{4}\right]$ and [bmpy $]\left[\mathrm{BF}_{4}\right]($ bmpy $=\mathrm{N}$-butyl-3-methylpyridinium) led to complete conversion within $1 \mathrm{~h}$ at 35 ${ }^{\circ} \mathrm{C}$ with CPA selectivities of 78-81\%. trans-Carveol, pinocarveol and less relevant side products such as iso-pinocamphone, trans-sobrerol and fencholenic aldehyde were formed. Much better catalytic performance was obtained with ILs containing the anion bis(trifluoromethylsulfonyl)imide $\left(\left[\mathrm{NTf}_{2}\right]^{-}\right),[$bmim $]\left[\mathrm{NTf}_{2}\right],[$ bmpy $]\left[\mathrm{NTf}_{2}\right]$ and $[\mathrm{Ch}]\left[\mathrm{NTf}_{2}\right](\mathrm{Ch}=$ choline), which gave complete PinOx conversion within 1 min and CPA selectivities of 86-94\%, with the excellent CPA yield of $94 \%$ being obtained with [bmpy][NTf $\left.{ }_{2}\right]$. The blank reaction of PinOx in [bmpy][$\left[\mathrm{NTf}_{2}\right]$ (i.e., without $\mathbf{1}$ ) showed no CPA formation after $30 \mathrm{~min}$.

The catalytic results obtained with the systems $\mathbf{1} / \mathrm{IL}$ are consistent with many other examples of catalysis in ILs in that the choice of the anion can strongly influence the reaction rate and selectivity. ${ }^{30,33}$ In accordance with the results obtained with 1, MTO displayed better performance for the isomerization of PinOx in [bmim] $\left[\mathrm{NTf}_{2}\right](100 \%$ conversion at $10 \mathrm{~min}, 60 \%$ CPA selectivity) than in $[\mathrm{bmim}]\left[\mathrm{BF}_{4}\right]$ (78\% conversion at $10 \mathrm{~min}, 35 \%$ CPA selectivity). ${ }^{31}$ When these two ILs have been compared as solvents in other acid-catalyzed reactions, such as in the benzolylation of aromatic substrates using metal salt catalysts, ${ }^{34,35}[\mathrm{bmim}]\left[\mathrm{NTf}_{2}\right]$ has frequently yielded better results. The anions $\left[\mathrm{BF}_{4}\right]^{-}$and $\left[\mathrm{NTf}_{2}\right]^{-}$impart very different physical properties to the respective ILs that may be responsible for the different catalytic performances observed. In particular, $\left[\mathrm{NTf}_{2}\right]^{-}$is hydrophobic, while $\left[\mathrm{BF}_{4}\right]^{-}$is hydrophilic, and the former has lower basicity/nucleophilicity. ${ }^{36,37}$ Costa et al. ${ }^{32}$ reported that enhanced basicity of the solvent may favor proton shifts of intermediates leading to side products such as trans-carveol and pinocarveol. Rocha et al. ${ }^{38}$ reported that (i) the isomerization of the carbenium ion (I) (Figure 1) 
Table 2. Isomerization of $\alpha$-pinene oxide to campholenic aldehyde in the presence of catalyst/ionic liquid combinations $^{a}$

\begin{tabular}{|c|c|c|c|c|}
\hline Catalytic system & Run & Time (min) & Conversion $(\%)$ & CPA yield (\%) \\
\hline \multirow[t]{2}{*}{$\mathbf{1} /[\mathrm{bmim}]\left[\mathrm{BF}_{4}\right]$} & 1 & 1 & 87 & 41 \\
\hline & & 60 & 100 & 81 \\
\hline \multirow[t]{2}{*}{$\mathbf{1} /[\mathrm{bmpy}]\left[\mathrm{BF}_{4}\right]$} & 1 & 1 & 92 & 47 \\
\hline & & 60 & 99 & 78 \\
\hline \multirow[t]{3}{*}{$\mathbf{1} /[\mathrm{bmim}]\left[\mathrm{NTf}_{2}\right]$} & 1 & 1 & 100 & 90 \\
\hline & 2 & 1 & 100 & 92 \\
\hline & 3 & 1 & 100 & 94 \\
\hline \multirow[t]{3}{*}{$\mathbf{1} /[\mathrm{bmpy}]\left[\mathrm{NTf}_{2}\right]$} & 1 & 1 & 100 & 94 \\
\hline & 2 & 1 & 100 & 85 \\
\hline & 3 & 1 & 100 & 52 \\
\hline \multirow[t]{5}{*}{$\mathbf{1} /[\mathrm{Ch}]\left[\mathrm{NTf}_{2}\right]$} & 1 & 1 & 100 & 86 \\
\hline & 2 & 1 & 100 & 91 \\
\hline & 3 & 1 & 100 & 95 \\
\hline & 4 & 1 & 100 & 98 \\
\hline & 5 & 1 & 100 & 98 \\
\hline \multirow[t]{3}{*}{$\mathbf{2} /[\mathrm{Ch}]\left[\mathrm{NTf}_{2}\right]$} & 1 & 1 & 100 & 80 \\
\hline & 2 & 1 & 100 & 59 \\
\hline & 3 & 1 & 100 & 38 \\
\hline \multirow[t]{3}{*}{$\mathrm{ZnCl}_{2} /[\mathrm{Ch}]\left[\mathrm{NTf}_{2}\right]$} & 1 & 1 & 100 & 98 \\
\hline & 2 & 1 & 100 & 75 \\
\hline & 3 & 1 & 100 & 55 \\
\hline
\end{tabular}

${ }^{a}$ Reaction conditions: $40 \mu \mathrm{mol}$ Mo or $\mathrm{W}$ complex or $\mathrm{ZnCl}_{2}, 0.82 \mathrm{mmol} \mathrm{PinOx}$, $[\mathrm{PinOx}]=0.9 \mathrm{M}, 35^{\circ} \mathrm{C}$. CPA yields at $30 \mathrm{~min}$ for blank reactions using the IL without catalyst were $14 \%$ for $[\mathrm{bmim}]\left[\mathrm{BF}_{4}\right], 36 \%$ for $[\mathrm{bmim}]\left[\mathrm{NTf}_{2}\right], 0 \%$ for [bmpy] $\left[\mathrm{BF}_{4}\right], 0 \%$ for $[\mathrm{bmpy}]\left[\mathrm{NTf}_{2}\right]$ and $34 \%$ for $[\mathrm{Ch}]\left[\mathrm{NTf}_{2}\right]$. 
may be sensitive to bonding with nucleophilic species such as anions present in the reaction medium, and (ii) stronger basic solvents (stronger proton-acceptor properties) may favor deprotonation pathways leading to (six-membered carbon ring) $p$-menthenic side products such as trans-carveol. Figure S3 in the Supporting Information shows possible side reactions involving intermediate (I) to byproducts such as pinocarveol, iso-pinocamphone, fencholenic aldehyde, and ( $p$-menthenic type) trans-carveol and trans-sobrerol. ${ }^{32}$ According to the mechanistic considerations discussed above, the relatively low nucleophilicity of the anion $\left[\mathrm{NTf}_{2}\right]^{-}$may avoid competitive interactions of the solvent with the substrate molecules in the coordination to the Lewis acid metal center, favoring PinOx conversion. ${ }^{8,20,32}$ On the other hand, the hydrophilic contribution from the cation of the IL may enhance the solubilization of the PinOx molecules. Other contributing factors may include viscosity and water content: the ILs with $\left[\mathrm{NTf}_{2}\right]^{-}$have lower viscosities and, in their as-received states, lower water contents when compared with the corresponding ILs with $\left[\mathrm{BF}_{4}\right]^{-}$(Table S2 in the Supporting Information). Although the ILs were vacuum-dried prior to use in the catalytic reactions, traces of water may still be present which could contribute to the formation of side products. ${ }^{38}$ Besides the solvent properties and reaction conditions, the acid properties of the catalyst may also influence the product distributions in different ways, depending on the catalytic system. ${ }^{32,38,39}$ The Lewis acidity of complex 1 coupled with an ideal IL solvent favors the (100\% atom economy) PinOx conversion to CPA which is formed in very high yields under approximately ambient conditions, which accounts for high reaction and energy efficiency and reduced waste production, in line with green chemistry principles.

For the ILs with $\left[\mathrm{NTf}_{2}\right]^{-}$, recycling of the catalyst/IL systems was performed in a manner similar to that carried out for the ethanolysis of StyOx in $[\mathrm{bmim}]\left[\mathrm{BF}_{4}\right]$. Gas chromatography was used to confirm the complete solvent extraction of the products from the $1 /[\mathrm{Ch}]\left[\mathrm{NTf}_{2}\right]$ system. The FT-IR spectrum of the IL phase after the extraction step matched the spectrum of the unused IL (Figure S2 in the Supporting Information). Between 3 and 5 catalytic runs were performed for each system (Table 2, Figure 2). The PinOx reaction was complete at $1 \mathrm{~min}$ for all cycles performed for each system. While CPA selectivity progressively decreased upon recycling of $\mathbf{1} /[\mathrm{bmpy}]\left[\mathrm{NTf}_{2}\right]$, the opposite trend was observed with $\mathbf{1} /[\mathrm{bmim}]\left[\mathrm{NTf}_{2}\right]$ and $\mathbf{1} /[\mathrm{Ch}]\left[\mathrm{NTf}_{2}\right]$. The yield for the latter system stabilized at the near-quantitative value of $98 \%$ for the fourth and fifth cycles. ${ }^{40}$ ICP-OES analysis indicated that the initial amount of molybdenum remained similar; 
9.4 and $9.8 \mathrm{mg}$ Mo per liter of IL for the fresh and recovered catalyst+IL system, respectively, which is within the experimental range of error (5-10\%). These results are consistent with the steady PinOx conversion in recycling runs, and validate the efficiency of the solvent extraction protocol used for the CPA product separation and recycling of the catalyst+IL system. To the best of our knowledge, this is the highest yield yet reported for the rearrangement of PinOx to CPA. In a separate experiment, the stability of CPA in this catalytic system was checked by using CPA as a substrate in the presence of $\mathbf{1} /[\mathrm{Ch}]\left[\mathrm{NTf}_{2}\right]$ (under similar reaction conditions to those used with PinOx as substrate), which led to negligible CPA conversion after $6 \mathrm{~h}$. Hence, the catalytic system $\mathbf{1} /[\mathrm{Ch}]\left[\mathrm{NTf}_{2}\right]$ did not decompose CPA.

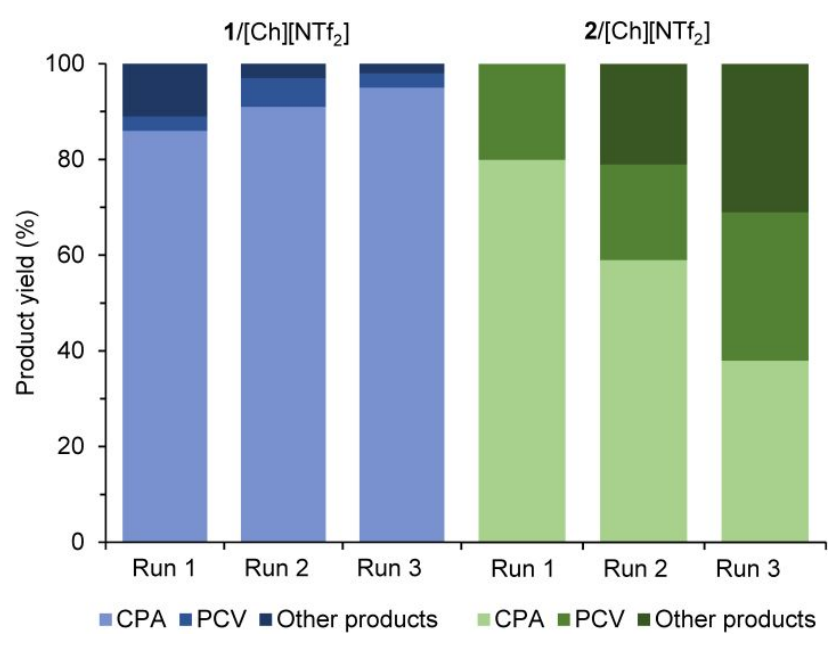

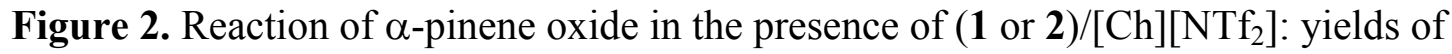
campholenic aldehyde (CPA), pinocarveol (PCV) and other products at 100\% PinOx conversion, $35^{\circ} \mathrm{C}, 1 \mathrm{~min}$ reaction, for three consecutive batch runs.

The performance of the system $\mathbf{1} /[\mathrm{Ch}]\left[\mathrm{NTf}_{2}\right]$ was compared with that for $\mathbf{2} /[\mathrm{Ch}]\left[\mathrm{NTf}_{2}\right]$ and $\mathrm{ZnCl}_{2} /[\mathrm{Ch}]\left[\mathrm{NTf}_{2}\right]$ (Table 2, Figure 2 ). Both of these systems led to complete conversion at 1 min for three reaction cycles. For the tungsten analogue 2, the CPA selectivity in the first run was slightly lower than that observed for $1(80 \%$ vs. $86 \%)$, with pinocarveol being the other product formed with $20 \%$ selectivity. In contrast to 1 , a drastic lowering of CPA selectivity was observed upon recycling, with increasing amounts of pinocarveol and other products being formed. Similarly, the system $\mathrm{ZnCl}_{2} /[\mathrm{Ch}]\left[\mathrm{NTf}_{2}\right]$ displayed poor recyclability, with CPA selectivity decreasing from $98 \%$ in the first run to $55 \%$ in the third run. One cannot rule out the 
possibility of $\mathrm{ZnCl}_{2}$ decomposing into different species in the ionic liquid medium, altering the acidic features.

Overall, this work shows that the molybdenum catalyst $\mathbf{1}$, when used with an effective ionic liquid solvent, may offer very high activity and selectivity in the conversion of PinOx to CPA, which is an industrially important reaction. A possible CPA production process using the recyclable ionic liquid-standing mixed-ring molybdenocene-type catalyst is proposed, which may be of interest for future engineering studies. A simplified Process Flow Diagram (PFD) for this catalytic process is given in Figure 3, where the catalytic reaction using a continuous stirred tank reactor (R1) is followed by the recovery of the desired CPA product using a vacuum distillation tower (T1), in a comparable fashion to that suggested in patented technology for PinOx conversion using a zinc halide (salt) catalyst and a solvent with a higher boiling point than CPA. ${ }^{19}$

The tower T1 is physically located above the reactor such that the IL+catalyst mixture may be recycled to the reactor under gravity (as mentioned above, the ILs with $\left[\mathrm{NTf}_{2}\right]^{-}$have lower viscosities). The CPA product is taken as a condensed overhead liquid stream. The tower T1 overhead pressure may be controlled by throttling a slip stream through the vacuum steam educator ED1. The bottoms temperature (of T1) may be the same or higher than the reactor temperature. The bottoms sump area height may provide the necessary height of liquid to, in turn, provide enough pressure drop across a control valve to allow recycling of the IL+catalyst mixture (stripped of product) back into the reactor R1, under bottoms level control. Further details of the overall process are given in the Supporting Information.

The proposed process advantageously avoids solvent extraction (used in our lab-scale studies) for separating the product from the catalyst, which would also require subsequent distillation of the extract to separate the volatile organic solvent from the desired CPA product. According to the process disclosed in the patent by Kane et al., ${ }^{19}$ our catalyst/solvent system may offer an advantage in that the high activity and stability it exhibits may prevent carryover of unreacted PinOx feed into the product during vacuum distillation, which was a limitation to cycle length in the patent. On the other hand, the byproduct drag stream (taken to control buildup of byproducts, Figure 3) is minimized by the exceptionally high selectivity exhibited by our catalyst/solvent system. The very high conversions reached with our catalyst/solvent system 
avoid additional distillation units to recycle PinOx and waste production. These features may permit enhanced economic and environmental sustainability.

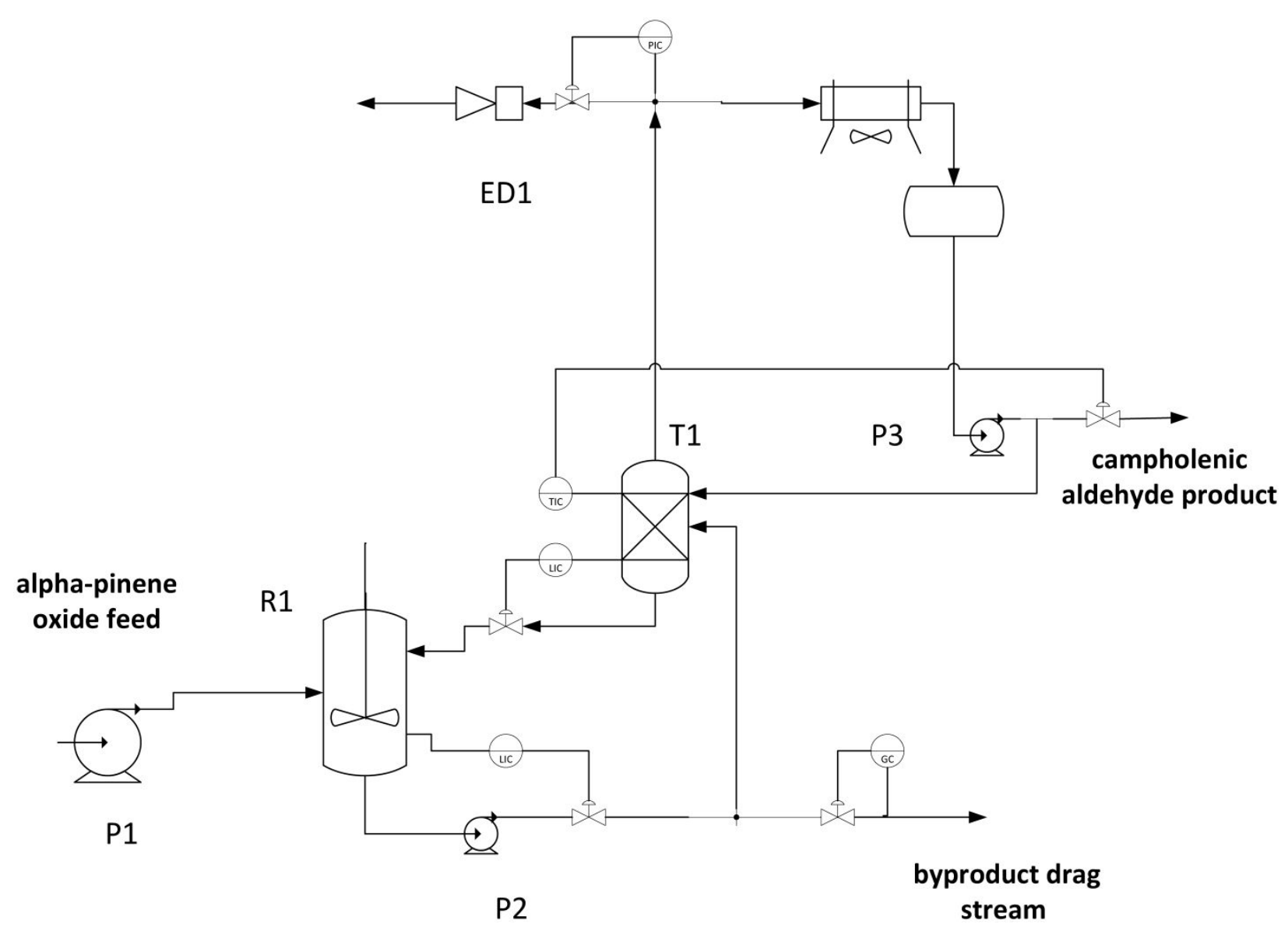

Figure 3. PFD for a possible process to convert $\alpha$-pinene oxide to campholenic aldehyde product over an ionic liquid-standing mixed-ring molybdenocene-type catalyst: stirred tank reactor R1, distillation tower T1, pumps P1-P3, vacuum steam educator ED1. Only some of the process controls are shown for the sake of clarity.

\section{CONCLUSION}

In summary, the cationic $\mathrm{Mo}^{\mathrm{IV}}$ complex $\left[\mathrm{IndCpMo}(\mathrm{MeCN})_{2}\right]\left(\mathrm{BF}_{4}\right)_{2}(\mathbf{1})$ can efficiently promote acid-catalyzed epoxide ring-opening reactions. The desired products, 2-ethoxy-2-phenylethanol from styrene oxide and campholenic aldehyde from $\alpha$-pinene oxide, can be obtained in excellent yield ( $100 \%$ or close) on a time-scale of minutes at approximately ambient temperature. For the ethanolysis of StyOx, the use of an IL as cosolvent allows recycling while not affecting catalytic performance. For the isomerization of PinOx, the nature of the anion in the IL strongly 
influenced catalytic activity, with those containing $\left[\mathrm{NTf}_{2}\right]^{-}$giving better results than those containing $\left[\mathrm{BF}_{4}\right]^{-}$(for the same cation). On the other hand, for the ILs with $\left[\mathrm{NTf}_{2}\right]^{-}$, the nature of the cation influenced the recycling performance. Selectivity to CPA increased in recycling runs for $[\mathrm{bmim}]^{+}$and $[\mathrm{Ch}]^{+}$, settling at $98 \%$ for the latter. As far as we know, this combination of activity, selectivity and recyclability is unprecedented for the liquid-phase catalytic isomerization of PinOx to CPA. A possible process Flow Diagram was designed for producing CPA continuously using the IL+catalyst system, where a stirred tank reactor is in line with a vacuum distillation tower for separating the target CPA product from the IL+catalyst mixture which is recycled back to the reaction. The proposed strategy is comparable to patented technologies, although it may benefit from the high activity, selectivity and relatively good stability of our catalytic system. Organomolybdenum complexes such as molybdenocene derivatives deserve further investigation as promoters of commercially relevant epoxide ring-opening reactions, such as the atom economic and sustainable transformation of $\alpha$-pinene oxide to campholenic aldehyde.

\section{ASSOCIATED CONTENT}

\section{Supporting Information}

The Supporting Information is available free of charge on the ACS Publications website at DOI: 10.1021/acssuschemeng.xxxxxxx.

Experimental procedures, FT-IR spectra, selected physical properties of the ILs used, mechanistic proposal for the conversion of PinOx to side products, table comparing literature data for the catalytic isomerization of $\alpha$-pinene oxide, full explanation of the PFD for a CPA production process.

\section{AUTHOR INFORMATION}

\section{Corresponding Authors}

*E-mail: atav@ua.pt

*E-mail: igoncalves@ua.pt 


\section{ACKNOWLEDGMENTS}

This work was carried out with the support of CICECO - Aveiro Institute of Materials [FCT (Fundação para a Ciência e a Tecnologia) Ref. UID/CTM/50011/2019], and the CENTRO 2020 Regional Operational Programme (Project References CENTRO-01-0145-FEDER-028031 and PTDC/QUI-QOR/28031/2017), co-financed by national funds through the FCT/MEC and the European Union (EU) through the European Regional Development Fund under the Portugal 2020 Partnership Agreement. The position held by S.M.B. was funded by national funds (OE), through FCT, I.P., in the scope of the framework contract foreseen in the numbers 4, 5 and 6 of article 23 of the Decree-Law 57/2016 of 29 August, changed by Law 57/2017 of 19 July.

\section{REFERENCES}

(1) Smith, J. G. Synthetically Useful Reactions of Epoxides. Synthesis 1984, 629-656.

(2) Pastor, I. M.; Yus, M. Asymmetric Ring Opening of Epoxides. Curr. Org. Chem. 2005, 9, 129.

(3) Pineschi, M.; Bertolini, F.; Di Bussolo, V.; Crotti, P. Regio- and Stereoselective Ring Opening of Allylic Epoxides. Curr. Org. Chem. 2009, 6, 290-324.

(4) Meninno, S.; Lattanzi, A. Organocatalytic Asymmetric Reactions of Epoxides: Recent Progress. Chem. Eur. J. 2016, 22, 3632-3642.

(5) Saddique, F. A.; Zahoor, A. F.; Faiz, S.; Naqvi, S. A. R.; Usman, M.; Ahmad, M. Recent trends in ring opening of epoxides by amines as nucleophiles. Synth. Commun. 2016, 46, 831868.

(6) Robinson, M. W. C.; Davies, A. M.; Buckle, R.; Mabbett, I.; Taylor, S. H.; Graham, A. E. Epoxide ring-opening and Meinwald rearrangement reactions of epoxides catalyzed by mesoporous aluminosilicates. Org. Biomol. Chem. 2009, 7, 2559-2564.

(7) Il'ina, I. V.; Volcho, K. P.; Salakhutdinov, N. F. Acid-Catalyzed Transformations of Pinane Terpenoids. New Prospects. Russ. J. Org. Chem. 2008, 44, 1-23.

(8) Kunkeler, P. J.; Van Der Waal, J. C.; Bremmer, J.; Zuurdeeg, B. J.; Downing, R. S.; van Bekkum, H. Application of zeolite titanium Beta in the rearrangement of $\alpha$-pinene oxide to campholenic aldehyde. Catal. Lett. 1998, 53, 135-138. 
(9) Alaerts, L.; Séguin, E.; Poelman, H.; Thibault-Starzyk, F.; Jacobs, P. A.; De Vos, D. E. Probing the Lewis Acidity and Catalytic Activity of the Metal-Organic Framework $\left[\mathrm{Cu}_{3}(\mathrm{btc})_{2}\right]$ $(\mathrm{BTC}=$ Benzene-1,3,5-tricarboxylate). Chem. Eur. J. 2006, 12, 7353-7363.

(10) Štekrová, M.; Kubů, M.; Shamzhy, M.; Musilová, Z.; Čejka, J. $\alpha$-Pinene oxide isomerization: role of zeolite structure and acidity in the selective synthesis of campholenic aldehyde. Catal. Sci. Technol. 2018, 8, 2488-2501.

(11) Yamazaki, S. An effective procedure for the synthesis of acid-sensitive epoxides: Use of 1methylimidazole as the additive on methyltrioxorhenium-catalyzed epoxidation of alkenes with hydrogen peroxide. Org. Biomol. Chem. 2010, 8, 2377-2385.

(12) Charbonneau, L.; Foster, X.; Kaliaguine, S. Ultrasonic and Catalyst-Free Epoxidation of Limonene and Other Terpenes Using Dimethyl Dioxirane in Semibatch Conditions. ACS Sustainable Chem. Eng. 2018, 6, 1224-12231.

(13) Neri, G.; Rizzo, G.; Arico, A. S.; Crisafulli, C.; De Luca, L.; Donato, A.; Musolino, M. G.; Pietropaolo, R. One-pot synthesis of naturanol from $\alpha$-pinene oxide on bifunctional $\mathrm{Pt}-\mathrm{Sn} / \mathrm{SiO}{ }_{2}$ heterogeneous catalysts: Part I: The catalytic system. Appl. Catal. A: Gen. 2007, 325, 15-24. (14) Castro, J. M.; Linares-Palomino, P. J.; Salido, S.; Altarejos, J.; Nogueras, M.; Sánchez, A. Enantiospecific synthesis, separation and olfactory evaluation of all diastereomers of a homologue of the sandalwood odorant Polysantol®. Tetrahedron 2005, 61, 11192-11203. (15) Srikrishna, A.; Neetu, G. Chiral synthons from campholenaldehyde: enantiospecific synthesis of diquinane and linear triquinanes. Tetrahedron: Asymmetry 2010, 21, 2067-2071. (16) Mäki-Arvela, P.; Shcherban, N.; Lozachmeur, C.; Russo, V.; Wärnå, J.; Murzin, D. Yu. Isomerization of $\alpha$-Pinene Oxide: Solvent Effects, Kinetics and Thermodynamics. Catal. Lett. 2019, 149, 203-214.

(17) Hölderich, W. F.; Röseler, J.; Heitmann, G.; Liebens, A. T. The use of zeolites in the synthesis of fine and intermediate chemicals. Catal. Today 1997, 37, 353-366.

(18) Kaminska, J.; Schwegler, M. A.; Hoefnagel, A. J.; van Bekkum, H. The isomerization of $\alpha-$ pinene oxide with Brønsted and Lewis acids. Rec. Trav. Chim. Pays-Bas 1992, 111, 432-437. (19) Kane, B. J.; Sanders, G. P.; Snow, J. W.; Erman, M. B. Process for obtaining alphacampholenic aldehyde. U.S. Patent 6,515,186 B2, 2003. 
(20) Pitínová-Štekrová, M.; Eliášová, P.; Weissenberger, T.; Shamzhy, M.; Musilová, Z.; Čejka, J. Highly selective synthesis of campholenic aldehyde over Ti-MWW catalysts by $\alpha$-pinene oxide isomerization. Catal. Sci. Technol. 2018, 8, 4690-4701.

(21) Bruno, S. M.; Gamelas, C. A.; Gomes, A. C.; Valente, A. A.; Pillinger, M.; Romão, C. C.; Gonçalves, I. S. Isomerization of $\alpha$-pinene oxide in the presence of indenyl allyl dicarbonyl molybdenum(II) and tungsten(II) complexes. Catal. Commun. 2012, 23, 58-61.

(22) Bruno, S. M.; Gomes, A. C.; Gamelas, C. A.; Abrantes, M.; Oliveira, M. C.; Valente, A. A.; Paz, F. A. A.; Pillinger, M.; Romão, C. C.; Gonçalves, I. S. Application of an Indenyl Molybdenum Dicarbonyl Complex in the Isomerisation of $\alpha$-Pinene Oxide to Campholenic Aldehyde. New J. Chem. 2014, 38, 3172-3180.

(23) Bruno, S. M.; Gomes, A. C.; Abrantes, M.; Valente, A. A.; Pillinger, M.; Gonçalves, I. S. Ring-opening of epoxides promoted by organomolybdenum complexes of the type $\left[\left(\eta^{5}-\right.\right.$ $\left.\left.\mathrm{C}_{5} \mathrm{H}_{4} \mathrm{R}\right) \mathrm{Mo}(\mathrm{CO})_{2}\left(\eta^{3}-\mathrm{C}_{3} \mathrm{H}_{5}\right)\right]$ and $\left[\left(\eta^{5}-\mathrm{C}_{5} \mathrm{H}_{5}\right) \mathrm{Mo}(\mathrm{CO})_{3}\left(\mathrm{CH}_{2} \mathrm{R}\right)\right]$. J. Organomet. Chem. 2015, 799800, 179-183.

(24) Nogueira, L. S.; Neves, P.; Gomes, A. C.; Valente, A. A.; Pillinger, M.; Gonçalves, I. S. Performance of a tetracarbonylmolybdenum(0) pyrazolylpyridine (pre)catalyst in olefin epoxidation and epoxide alcoholysis. J. Organomet. Chem. 2017, 846, 185-192.

(25) Bruno, S. M.; Gonçalves, I. S.; Pillinger, M.; Romão, C. C.; Valente, A. A. Acid-catalyzed epoxide alcoholysis in the presence of indenyl molybdenum carbonyl complexes. J. Organomet. Chem. 2018, 855, 12-17.

(26) Breno, K. L.; Ahmed, T. J.; Pluth, M. D.; Balzarek, C.; Tyler, D. R. Organometallic chemistry in aqueous solution: Reactions catalyzed by water-soluble molybdocenes. Coord. Chem. Rev. 2006, 250, 1141-1151.

(27) Gamelas, C. A.; Herdtweck, E.; Lopes, J. P.; Romão, C. C. Redox-Induced Indenyl Slippage in $[\text { IndCpMoL } 2]^{2+/+/ 0}$ Complexes. Organometallics 1999, 18, 506-515.

(28) Trost, B. M.; Ryan, M. C. Indenylmetal Catalysis in Organic Synthesis. Angew. Chem. Int. Ed. 2017, 56, 2862-2879.

(29) The undissolved solids were recovered and recrystallized from $\mathrm{MeCN}$, giving solids with FT-IR spectra that matched those of complexes $\mathbf{1}$ and 2. Details are given in the Supporting Information. 
(30) Pârvulescu, V. I.; Hardacre, C. Catalysis in Ionic Liquids. Chem. Rev. 2007, 107, 26152665.

(31) Bruno, S. M.; Pillinger, M.; Kühn, F. E.; Gonçalves, I. S.; Valente, A. A. Isomerization of $\alpha$-pinene oxide in the presence of methyltrioxorhenium(VII). Catal. Commun. 2013, 35, 40-44. (32) Costa, V. V.; da Silva Rocha, K. A.; de Sousa, L. F.; Robles-Dutenhefner, P. A.; Gusevskaya, E. V. Isomerization of $\alpha$-pinene oxide over cerium and tin catalysts: Selective synthesis of trans-carveol and trans-sobrerol. J. Mol. Catal. A: Chem. 2011, 345, 69-74. (33) Hallett, J. P.; Welton, T. Room-Temperature Ionic Liquids: Solvents for Synthesis and Catalysis. 2. Chem. Rev. 2011, 111, 3508-3576.

(34) Gmouh, S.; Yang, H.; Vaultier, M. Activation of Bismuth(III) Derivatives in Ionic Liquids: Novel and Recyclable Catalytic Systems for Friedel-Crafts Acylation of Aromatic Compounds. Org. Lett. 2003, 5, 2219-2222.

(35) Goodrich, P.; Hardacre, C.; Mehdi, H.; Nancarrow, P.; Rooney, D. W.; Thompson, J. M. Kinetic Study of the Metal Triflate Catalyzed Benzoylation of Anisole in an Ionic Liquid. Ind. Eng. Chem. Res. 2006, 45, 6640-6647.

(36) Yuan, X.; Yan, N.; Katsyuba, S. A.; Zvereva, E. E.; Kou, Y.; Dyson, P. J. A remarkable anion effect on palladium nanoparticle formation and stabilization in hydroxyl-functionalized ionic liquids. Phys. Chem. Chem. Phys. 2012, 14, 6026-6033.

(37) Thomas, P. A.; Kabanda, M. M.; Ebenso, E. E. DFT Investigation into the Role of Conventional and Ionic Liquids as Solvents in Olefin Metathesis. Int. J. Electrochem. Sci. 2013, 8, 10827-10838.

(38) K. A. da Silva Rocha, J. L. Hoehne, E. V. Gusevskaya, Phosphotungstic Acid as a Versatile Catalyst for the Synthesis of Fragrance Compounds by $\alpha$-Pinene Oxide Isomerization: SolventInduced Chemoselectivity, Chem. Eur. J. 2008, 14, 6166-6172.

(39) Wilson, K.; Rénson, A.; Clark, J. H. Novel heterogeneous zinc triflate catalysts for the rearrangement of $\alpha$-pinene oxide. Catal. Lett. 1999, 61, 51-55.

(40) The improved performances could arise from the progressive removal of impurities (e.g. water) from the IL since solvent extraction and drying of the catalyst/IL were carried out between consecutive reuses. It is a known fact that ILs contain impurities that may impact on catalytic performances. 


\section{For Table of Contents Use Only}

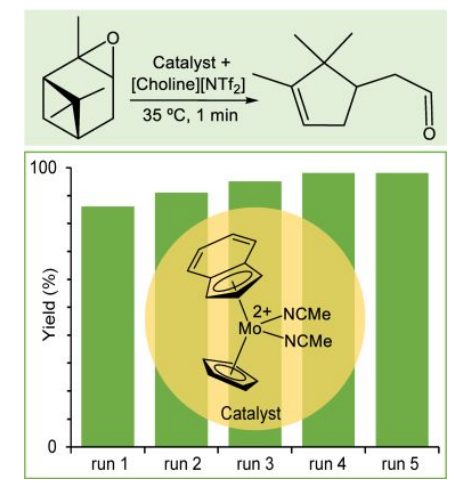

An efficient catalytic process for the atom economic conversion of a biorenewable terpene derivative to a valuable fine chemical is reported. 


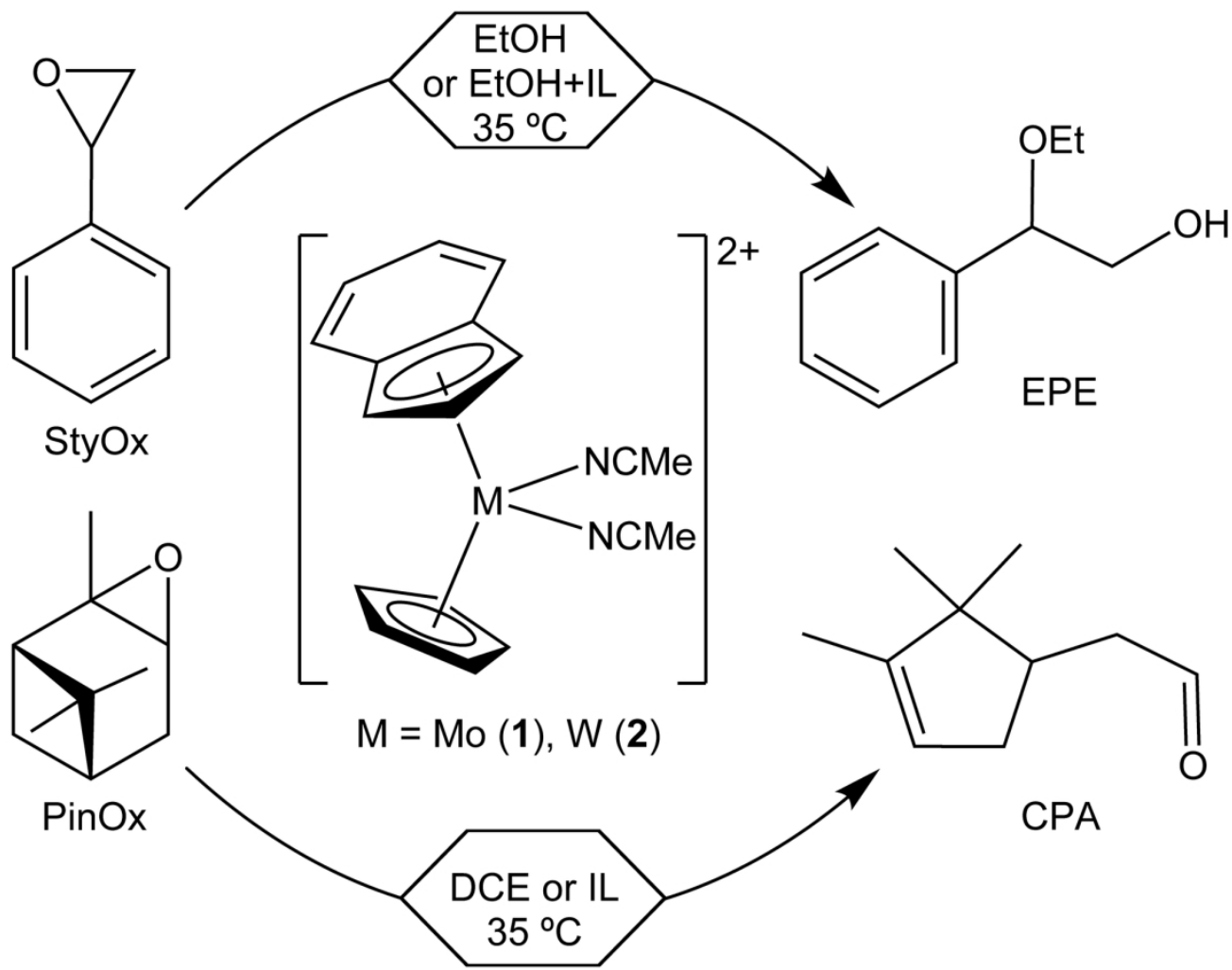

Scheme 1. Ethanolysis of styrene oxide to give 2-ethoxy-2-phenylethanol, and isomerization of a-pinene oxide to campholenic aldehyde, in the presence of $\mathbf{1}$ and $\mathbf{2}$ (DCE = 1,2-dichloroethane; IL = ionic liquid).

$$
81 \times 63 \mathrm{~mm}(600 \times 600 \mathrm{DPI})
$$




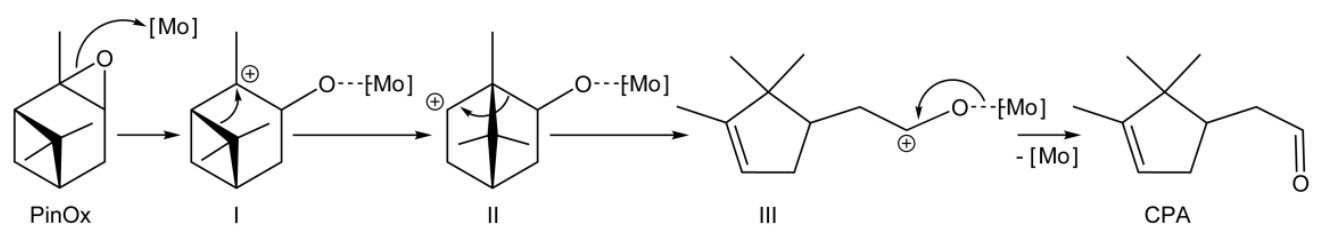

Figure 1. Mechanistic proposal of the conversion of PinOx to CPA in the presence of $\mathbf{1}$ ([Mo] represents complex 1). $164 \times 28 \mathrm{~mm}(600 \times 600 \mathrm{DPI})$ 


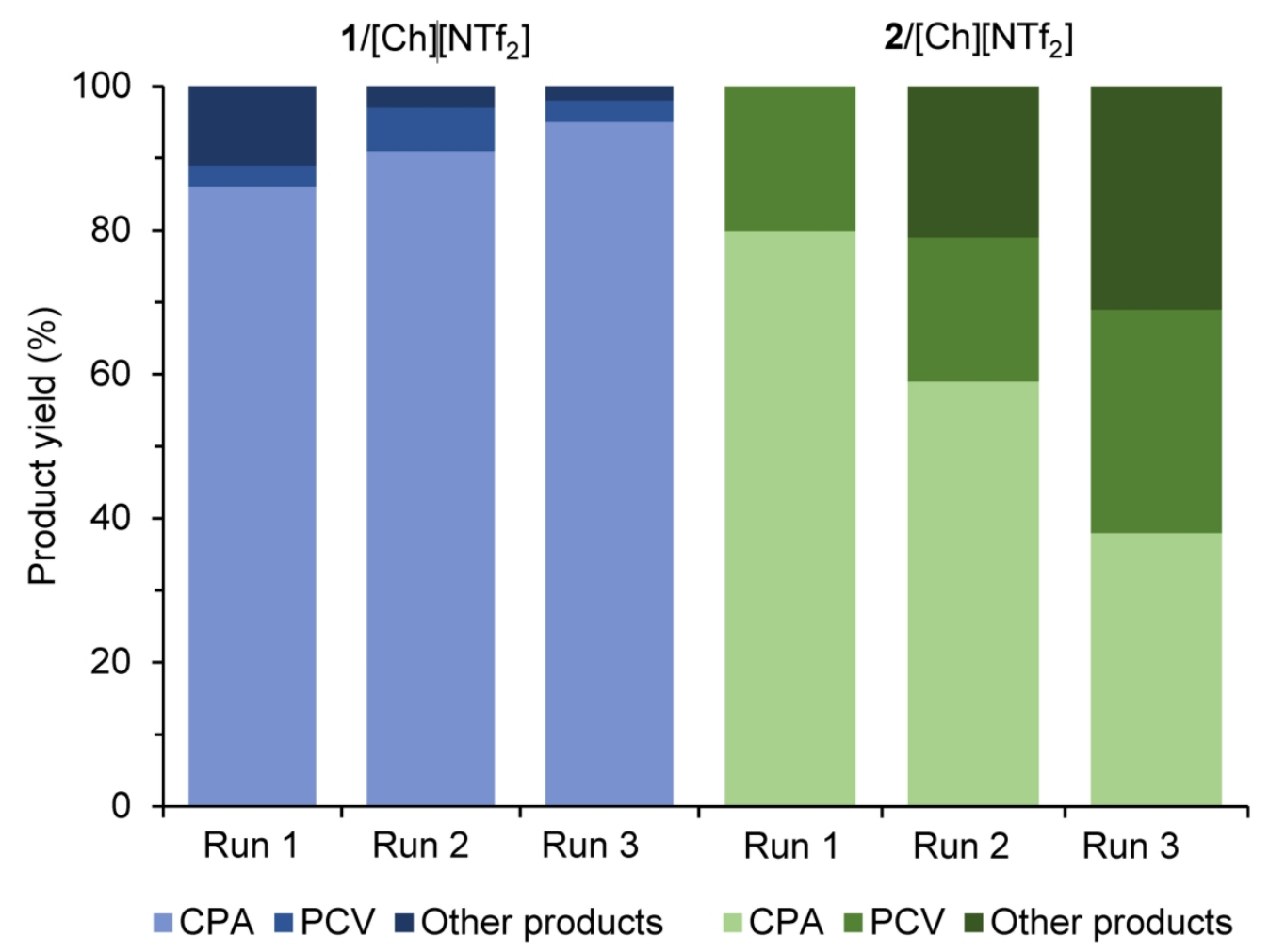

Figure 2. Reaction of a-pinene oxide in the presence of ( $\mathbf{1}$ or $\mathbf{2}) /[\mathrm{Ch}]\left[\mathrm{NTf}_{2}\right]$ : yields of campholenic aldehyde (CPA), pinocarveol (PCV) and other products at $100 \%$ PinOx conversion, $35^{\circ} \mathrm{C}, 1$ min reaction, for three consecutive batch runs.

\section{$82 \times 62 \mathrm{~mm}(600 \times 600 \mathrm{DPI})$}


Figure 3. PFD for a possible process to convert a-pinene oxide to campholenic aldehyde product over an ionic liquid-standing mixed-ring molybdenocene-type catalyst: stirred tank reactor R1, distillation tower T1, pumps P1-P3, vacuum steam educator ED1. Only some of the process controls are shown for the sake of clarity.

$165 \times 118 \mathrm{~mm}(300 \times 300 \mathrm{DPI})$ 

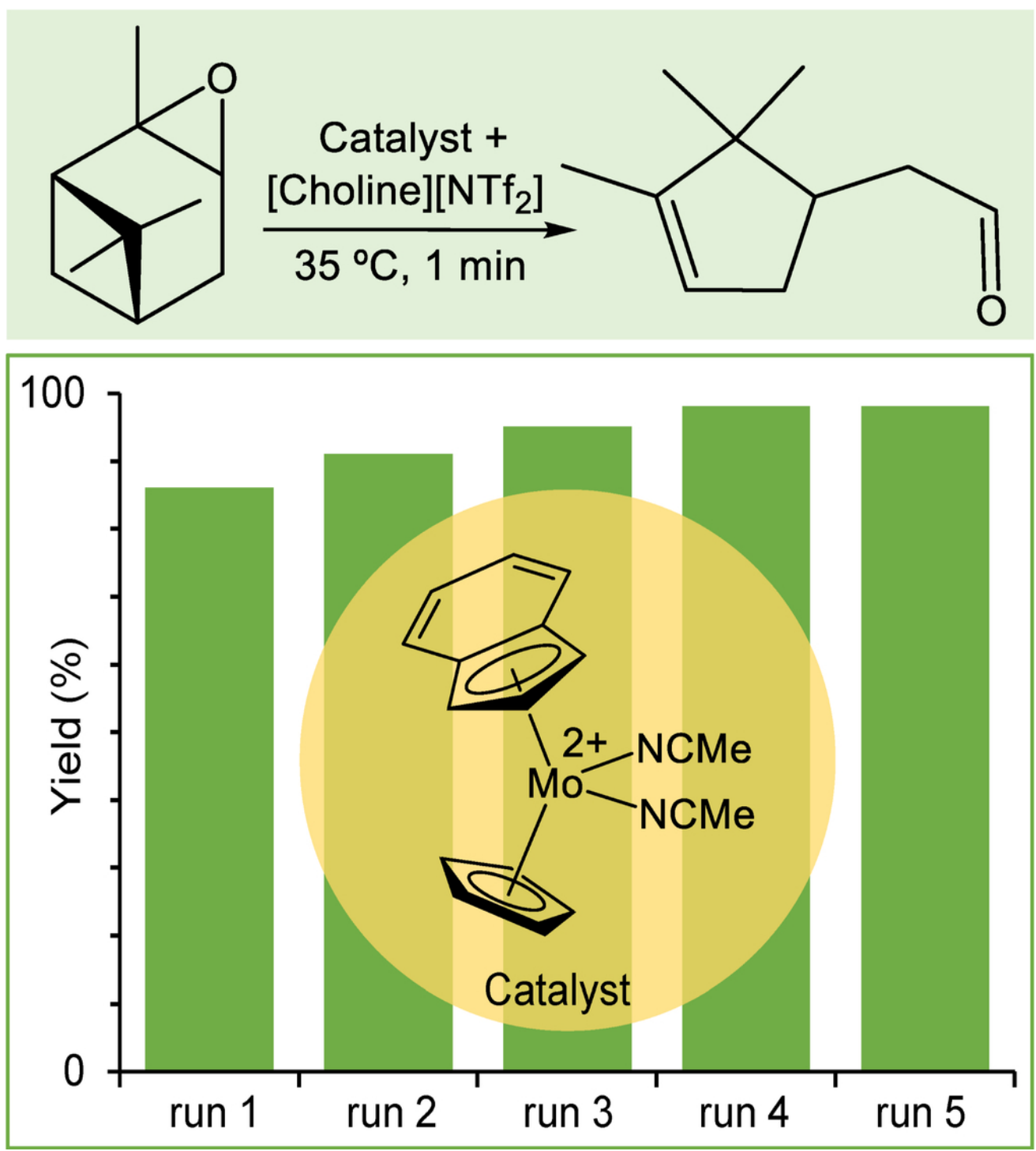

Graphical Abstract

$42 \times 47 \mathrm{~mm}(600 \times 600 \mathrm{DPI})$ 